\title{
PERAN PEREMPUAN DALAM PENCEGAHAN STUNTING DI KECAMATAN BUNAKEN KOTA MANADO PROVINSI SULAWESI UTARA
}

\author{
Jean Fanny Junita Timban ${ }^{1}$, Ellen Grace Tangkere ${ }^{2}$, Jelly Ribka Danaly Lumingkewas ${ }^{3}$ \\ 1,2,3 Program Studi Agribisnis Fakultas Pertanian Universitas Sam Ratulangi Jalan Kampus Kleak Manado \\ Provinsi Sulawesi Utara
}

E-mail koresponden : jean_timban@yahoo.com

\begin{abstract}
Stunting in under-five children is a reduced growth rate primarily caused by chronic undernutrition that leads to a child having height much less than is normal for age. This condition manifests mostly after two years old. The definition of stunting according to the World Health Organization (WHO) is for the "height for age" value to be less than two standard deviations of the WHO Child Growth Standards median. Indonesia has been plagued recently with stunting. In 2015, the World Bank indicates that stunting has cost 3 to 11 percent of the gross domestic product. Previous research works have documented that mothers play an important role in preventing stunting through antenatal care and child nursing. The objective of this study is to explore the role played by the mothers in Bunaken, Manado, in antenatal care and child nursing that prevent stunting. Samples are drawn using purposive sampling and data are analysis descriptively. The results show that the mothers' roles include taking antenatal check up to four times during pregnancy, daily use of FE 90 pill, participating in pregnancy counseling and care, delivery by health professionals, attending integrated service post (posyandu), visiting health professionals for postnatal care, completing universal immunization on child over 12 months old, and participating in educational activities for under-five nursing and nutritional fulfillment at least once a month. Of these eight recorded roles, however, there are merely $20 \%$ mothers indicate they regularly taking part in pregnancy counseling and care. Furthermore, only one percent $(n=3)$ respondents that report they attending educational activities for under-five nursing and nutritional fulfillment.
\end{abstract}

Keyword : peran; partisipasi; perempuan; pencegahan; stunting

\section{PENDAHULUAN}

Perempuan dalam pembangunan sedikitnya mengandung dua pengertian yakni, yang pertama adalah pembangunan dapat memberi kemudahan bagi perempuan untuk ikut berupaya meningkatkan diri dan keluarga. Kedua, pembangunan juga memberi kemudahan bagi perempuan untuk menyalurkan tenaga, ketrampilan, pikiran serta keahlian dalam proses pembangunan (Renette dkk, 1994). Pudjiwati Sajogyo (1983), menyebutkan bahwa dalam proses pembangunan yang mengikut sertakan perempuan, bukan saja akan membawa dampak positif terhadap lajunya pertumbuhan ekonomi negara tetapi juga merupakan suatu tindakan yang efisien, karena dengan ikut sertanya wanita dalam pembangunan memanfaatkan sumber manusia berpotensi.

Kemampuan perempuan perlu dikembangkan melalui peningkatan penguasaan ilmu pengetahuan dan teknologi, ketrampilan serta ketahanan mental spiritual agar dapat memanfaatkan kesempatan berperan aktif di segala kehidupan bangsa dan dalam segenap kegiatan pembangunan. Dalam kaitan dengan ini perlu dikembangkan iklim sosial budaya yang mendukung upaya peningkatan harkat dan martabat perempuan sehingga dapat semakin berperan aktif dalam masyarakat wanita sehingga dapat semakin berperan aktif dalam 
masyarakat, disamping lingkunga keluarganya (Sampoel, 1997).

Selanjutnya Munandar (1995), menyatakan bahwa peran perempuan dimasa sekarang sudah tidak lagi dikaitkan hanya dengan kodratnya sebagai seorang isteri atau ibu saja, namun telah berkembang sedemikian rupa sehingga perempuan telah berperan dalam setiap segi kehidupan masyarakat. Karena perempuan sekarang dapat mengembangkan diri pribadinya, dan turut serta menyumbangkan darmanya kepada masyarakat.

Peran perempuan berkaitan erat dengan status kedudukan dalam rumah tangga maupun masyarakat luas umumnya. Menurut Pudjiwati Sajogyo (1983) dibedakan atas 2 bagian besar, yaitu : Peranan di dalam keluarga sebagai tenaga kerja 'domestic labour' yang berhubungan dengan masalah mengurus rumah tangga, Peranan di luar keluarga meliputi usaha mencari nafkah untuk memperoleh penghasilan ataupun menambah penghasilan keluarga serta jangkauan sosial terhadap pelbagai kegiatan di luar rumah tangga.

Perempuan sebagai salah satu anggota keluarga seperti juga anggota keluarga lainnya, mempunyai tugas dan fungsi dalam mendukung kehidupan keluarga. Sejalan dengan semakin banyaknya bidang-bidang kehidupan dalam masyarakat dan semakin beratnya beban ekonomi keluarga, maka peran wanita dalam masyarakat dan keluarga menjadi semakin penting.

Stunting adalah kondisi gagal tumbuh pada anak balita (bayi dibawah 5 tahun) akibat dari kekurangan gizi kronis sehingga anak terlalu pendek untuk usianya (TNP2K). Stunting baru Nampak setelah bayi berusia 2 tahu. Balita pendek (stunting) dan sangat pendek adalah balita dengan Panjang badan atau tinggi badan menurut umurnya dibandingkan dengan standart baku WHO. Indonesia saat ini tengah bermasalah dengan stunting. Hasil Riset Kesehatan Dasar (Riskesdas) kementerian Kesehatan tahun 2013 menunjukan prevelensi stunting di Indonesia mencapai 37,2\%. Stunting bukan hal sepele, hasil riset Bank Dunia menggambarkan kerugian akibat stunting mencapai 3 - 11\% PDB 2015 atau sebesar Rp. 11.000 Triliun. Kerugian ekonomi akibat stunting di Indonesia diperkirakan mencapai Rp. 300 triliun -Rp. 1.210 triliun per tahun. Besarnya kerugian yang ditanggung pemerintah akibat stunting lantaran naiknya pengeluaran pemerintah terutama jaminan kesehatan nasional yang berhubungan dengan penyakit tidak menular seperti : jantung, stroke, diabetes ataupun gagal ginjal. Ketika dewasa anak yang mengalami stunting mudah mengalami kegemukan sehingga rentan terhadap serangan penyakit tidak menular seperti : jantung, stroke, diabetes ataupun gagal ginjal. Pemerintah telah meluncurkan rencana aksi nasional penanganan stunting pada bulan Agustus 2017, yang menekankan pada kegiatan konvergensi di tingkat nasional, daerah dan desa/kelurahan untuk memprioritaskan kegiatan intervensi gizi spesifik dan gizi sensitive pada 1000 hari pertama kehidupan sampai dengan usia 6 tahun.

Kota Manado mengalami permasalahan tingginya angka balita yang memiliki berat badan dibawah garis merah Kartu Menuju Sehat (KMS) pada penimbangan bayi di posyandu. Data Profil Kesehatan Sulawesi Utara tahun 2016, Kota Manado memiliki angka Bayi dengan berat badan dibawah garis merah sebesar 2,3\% atau 548 Balita. Balita yang dibawah garis merah berpotensi menjadi stunting jika tidak ditangani dengan secara konvergensi. Perempuan atau ibu hamil dan ibu yang memiliki balita sangat berperan dalam mencegah terjadinya bayi stunting terutama pada 1000 hari pertama kehidupan (HPK).

\section{KAJIAN LITERATUR}

\subsection{Peran Perempuan}

Perempuan diberbagai masyarakat, memainkan banyak peran. Perempuan sebagai ibu, isteri, petani, buruh, guru, pengelola perusahaan, pekerja sukarela dan lain-lain. Banyak perempuan yang memainkan peran ganda atau lebih di masyarakat. Beberapa masyarakat memberi kedudukan terhormat kepada perempuan, masyarakat lainnya menganggap peran perempuan 
kurang penting ketimbang pria (Munandar, 2005). Seorang perempuan sebagai isteri dan ibu dalam keluarga melaksanakan tugas dan kewajiban khususnya dalam melayani suami, memelihara dan membesarkan serta membimbing dan mendidik anak-anak. Dalam melaksanakan tugas ini perempuan melaksanakan pembangunan bangsa dari bawah, yaitu dari sel masyarakat terkecil atau wadah dasar dari suatu bangsa. Langkah pertama dari apa yang dilaksanakan seorang perempuan sebagai isteri dan ibu sudah merupakan aspek sosial kemasyarakatan, yaitu membesarkan, membimbing, dan mendidik anak-anak, serta juga melayani suami; yang merupakan bagian atau unsur-unsur terkecil dari kehidupan sosial kemasyarakatan (Peck, 2001). Selanjutnya perempuan sebagai mahluk sosial tidak terlepas dari kaitannya dengan lingkungan sosial dalam masyarakat. Perempuan mempunyai kesempatan yang luas untuk ikut serta dalam kegiatan-kegiatan kemasyarakatan. Perempuan dapat aktif dalam masyarakat melalui kegiata-kegiatan seperti : guru, dosen, pegawai dan lain-lain. Kegiatan ini mempunyai tempat tersendiri dalam arti, selain tugas dan kewajiban sebagai isteri dan ibu dalam rumah tangga, perempuan dapat pula berperan melalui kegiatankegiatan tersebut diatas. Perempuan yang mempunyai profesi seperti ini harus membagi waktunya dengan baik agar tugas dan kewajiban sebagai isteri tidak terganggu. Menentukan dan membagi waktu agar tugas keluarga tidak dikurangi dan tidak dikesampingkan merupakan suatu beban dan tantangan bagi setiap ibu

\subsection{Stunting}

Stunting adalah kondisi dimana balita memiliki panjang atau tinggi badan yang kurang jika dibandingkan dengan umur. (WHO). Kondisi ini diukur dengan panjang atau tinggi badan yang lebih dari minus dua standart deviasi median standart pertumbuhan anak dari WHO. Balita stunting termasuk masalah gizi kronik yang disebabkan oleh banyak faktor seperti sosial ekonomi, gizi ibu saat hamil, kesakitan pada bayi, dan kurangnya asupan gizi pada bayi.(Buletin Stunting, 2018). Stunting menggambarkan status gizi kurang yang bersifat kronik pada masa pertumbuhan dan perkembangan sejak awal kehidupan. Keadaan ini dipresentasikan dengan nilai z-score tinggi badan menurut umur (TB/U) kurang dari -2 standar deviasi (SD) berdasarkan standar pertumbuhan menurut WHO (WHO, 2010). Secara global, sekitar 1 dari 4 balita mengalami stunting (UNICEF, 2013). Di Indonesia, berdasarkan hasil riset kesehatan dasar (Riskesdas) tahun 2013, terdapat 37,2\% balita yang mengalami stunting. Diketahui dari jumlah presentase tersebut, 19,2\% anak pendek dan 18,0\% sangat pendek. Prevalensi stunting ini mengalami peningkatan dibandingkan hasil Riskesdas tahun 2010 yaitu sebesar 35,6\%. Masa balita merupakan periode yang sangat peka terhadap lingkungan sehingga diperlukan 14 Media Gizi Indonesia, Vol. 10, No. 1 Januari-Juni 2015: hlm. 13-19 perhatian lebih terutama kecukupan gizinya (Kurniasih, 2010). Masalah gizi terutama stunting pada balita dapat menghambat perkembangan anak, dengan dampak negatif yang akan berlangsung dalam kehidupan selanjutnya seperti penurunan intelektual, rentan terhadap penyakit tidak menular, penurunan produktivitas hingga menyebabkan kemiskinan dan risiko melahirkan bayi dengan berat lahir rendah (UNICEF, 2012; dan WHO, 2010). Status gizi ibu hamil sangat memengaruhi keadaan kesehatan dan perkembangan janin. Gangguan pertumbuhan dalam kandungan dapat menyebabkan berat lahir rendah (WHO, 2014). Penelitian di Nepal menunjukkan bahwa bayi dengan berat lahir rendah mempunyai risiko yang lebih tinggi untuk menjadi stunting (Paudel, et al., 2012).

\section{METODE}

Penelitian ini menggunakan data primer dan data sekunder. Dimana data primer diperoleh dari wawancara langsung pada responden menggunakan daftar pertanyaan sedangkan data sekunder diperoleh dari instansi yang terkait dengan penelitian. Metode pengambilan sampel dalam penelitian ini dilakukan secara "Purposive Sampling", yaitu teknik pengambilan sampel dengan kriteria-kriteria tertentu. Responden yang dipilih 
sebanyak 50 responden, yaitu perempuan yang berstatus sebagai ibu rumah tangga yang memiliki anak balita. Data yang dihasilkan dalam penelitian disajikan dalam bentuk deskriptif.

\section{HASIL DAN PEMBAHASAN}

\subsection{Deskripsi Lokasi Penelitian}

Kecamatan Bunaken terdiri dari 5 kelurahan yaitu Kelurahan Pandu, Bilang, Molas dan tongkaeina, dengan batas wilayah sebagai berikut :

Sebelah utara dengan Kabupaten Minahasa Utara, sebelah timur dengan Kecamatan Tuminting, sebelah selatan dengan Kecamatan Tuminting dan sebelah barat dengan laut Manado. Luas wilayah kecamatan Bunaken dapat dlihat pada tabel 1.1

Tabel 1.1 LUAS WILAYAH KELURAHAN DI KECAMATAN BUNAKEN

\begin{tabular}{|l|l|l|l|}
\hline NO & \multicolumn{1}{|c|}{ KELURAHAN } & \multicolumn{1}{|c|}{ LUAS (HA) } & KETERANGAN \\
\hline 1. & PANDU & 863,7 & \\
\hline 2. & BAILANG & 737,89 & \\
\hline 3. & MOLAS & 912 & \\
\hline 4. & MERAS & 665 & \\
\hline 5. & TONGKEINA & 858 & \\
\hline
\end{tabular}

\subsection{Penduduk}

Kecamatan Bunaken memiliki jumlah penduduk sebesar 21,772 jiwa dengan yang terdiri dari 5,316 rumah tangga. Adapun jumlah penduduk berdasarkan kelurahan dapat dilihat pada tabel 1.2

Tabel 1.2 JUMLAH PENDUDUK DI KECAMATAN BUNAKEN

\begin{tabular}{|l|l|c|c|}
\hline NO & \multicolumn{1}{|c|}{ KELURAHAN } & PENDUDUK & $\begin{array}{r}\text { RUMAH } \\
\text { TANGGA }\end{array}$ \\
\hline 1. & PANDU & 5910 & 1593 \\
\hline 2. & BAILANG & 7411 & 1856 \\
\hline 3. & MOLAS & 5214 & 1585 \\
\hline 4. & MERAS & 1128 & 317 \\
\hline 5. & TONGKEINA & 2109 & 590 \\
\hline
\end{tabular}

\subsection{Karakteristik Responden}

Responden yang menjadi sampling penelitian ini adalah ibu hamil dan ibu yang memiliki balita untuk diteliti bagaimana pola perawatan sewaktu kehamilan dan pola pengasuhan anak setelah melahirkan sampai bayi berumur 2 tahun. Pola perawatan waktu kehamilan serta pola pengasuhan anak sangat mempengaruhi tumbuh kembang anak, asupan gizi anak. Adapun jumlah responden ibu hamil dan ibu yang memiliki balita adalah seperti tabel 1.3 
Tabel. 1.3 Jumlah Responden berdasarkan kategori kehamilan dan ibu yang memiliki balita.

\begin{tabular}{|l|l|c|c|}
\hline NO & \multicolumn{1}{|c|}{ KELURAHAN } & IBU HAMIL & $\begin{array}{c}\text { IBU YANG } \\
\text { MEMILIKI } \\
\text { BALITA }\end{array}$ \\
\hline 1. & PANDU & 10 & 5 \\
\hline 2. & BAILANG & 10 & 5 \\
\hline 3. & MOLAS & 10 & 5 \\
\hline 4. & MERAS & 10 & 5 \\
\hline 5. & TONGKEINA & 10 & 5 \\
\hline
\end{tabular}

\subsection{Tingkat Pendidikan}

Peran pendidikan formal sangat berpengaruh terhadap pengetahuan dan sikap responden dalam merawat kehamilan dan pengasuhan anak balita. 68\% responden berpendidikan Sekolah Menengah Atas (SMA)

Tabel 1.4 Jumlah Responden Menurut Tingkat Pendidikan

\begin{tabular}{|l|l|c|c|}
\hline NO & \multicolumn{1}{|c|}{ Kelurahan } & $\begin{array}{l}\text { Jumlah } \\
\text { Responden }\end{array}$ & Persentase \\
\hline 1. & SD & 0 & 0 \\
\hline 2. & SLTP & 15 & 20 \\
\hline 3. & SLTA & 51 & 68 \\
\hline 4. & S1 & 9 & 12 \\
\hline 5. & S2 & 0 & 0 \\
\hline
\end{tabular}

4.4 Ibu hamil memeriksa kehamilan pad bidan minimal 4 kali selama masa kehamilan

Dari 50 responden ibu hamil, 48 responden menyatakan rutin memeriksa kehamilan di puskesmas atau posyandu. 2 responden tidak memeriksa rutin kehamilan dengan alasan domisili tempat tinggal jauh dari puskesmas ataupun posyandu. Menurut responden, mereka memeriksa kehamilan nanti pada saat dekat melahirkan. Hal ini dapat mempengaruhi kesehatan janin dan berdampak akan kondisi kesehatan bayi yang akan dilahirkan atau beresiko bayi lahir stunting.

\subsection{Ibu hamil minum pil Fe (penambah darah) selama masa kehamilan}

Selama masa kehamilan ,ibu hamil rentan mengalami anemia atau kekurangan sel darah merah. Kekurangan sel darah merah akan menyebabkan dampak yang tidak baik bagi pertumbuhan janin. (WHO,2017). Riskesdas 2017 menyatakan prevelensi anemia pada ibu hamil di Indonesia mencapai 37\%. Minum pil Fe selama masa kehamilan akan mengurangi gejala kekurangan sel darah merah.

Keasadaran ibu hamil untuk minum pil Fe pada responden di kecamatan Bunaken cukup tinggi yaitu mencapai $100 \%$. Hal ini disebabkan sosialisasi yang rutin dilakukan oleh puskesmas dan posyandu serta pemberian pil Fe gratis kepada ibu hamil.

\subsection{Ibu hamil hadir dalam konseling dan perawatan kehamilan}


Konseling sangat membantu ibu hamil dalam konsultasi psikologi serta cara perawatan kehamilan yang benar. Dari 50 responden ibu hamil, hanya 10 responden atau (20\%) yang menyatakan hadir dalam konseling saat kunjungan posyandu, itupun dilakukan karena ibu hamil tersebut memiliki keluhan yang akan dikonsultasikan. Beberapa respnden menyatakan bahwa konseling sudah dilakukan pada saat pemeriksaan kehamilan baik di posyandu maupun puskesmas.

\subsection{Proses kelahiran ditangani oleh bidan}

Penanganan proses kelahiran yang dilakukan oleh bidan akan lebih aman karena ditangani oleh ahlinya. Hasil wawancara dengan responden, masih ada ibu yang melahirkan ditangani oleh bukan bidan. Responden yang bernama Kasmah Manangi mengatakan di kampung mereka tidak ada bidan sehingga proses melahirkan ditangani oleh biyang kampung. Pertolongan oleh biyang akan beresiko kelahiran yang tidak normal.

\subsection{Rutin hadir dalam posyandu}

Dengan rutin hadir dalam posyandu, ibu dan bayi akan mendapatkan pelayanan penimbangan bayi, konsultasi gizi dan vitamin A. Keseluruhan responden menyatakan rutin hadir dalam posyandu dan melakukan penimbangan bayi serta memperoleh vitamin A bagi balita dua kali dalam setahun.

\subsection{Melakukan perawatan nifas (termasuk bayinya) oleh bidan atau dokter}

Seluruh responden menyatakan bahwa selalu melakukan perawatan nifas dan bayi dua kali selama 42 hari sesudah kelahiran. Hal ini lakukan untuk menjaga kesehatan ibu dan anak. Perawatan nifas perlu untuk memantau kesehatan ibu dan bayi agar terpantau gizi bayi tersebut.

\subsection{Melakukan imunisasi lengkap setisp bayi diatas 12 bulan}

Imunisasi lengkap dilakukan oleh seluru responden, kesadaran ibu untuk mermbawa balita utuk imunisasi sudah sangat tinggi. 100\% responden mengatakan bahwa balita mereka sudah di imunisasi lengkap. Jemput bola yang dilakukan oleh puskesmas dan posyandu untuk menjangkau ibu - ibu yang memiliki balita yang jauh dari akses puskesmas adalah kunci keberhasilan imunisasi di kecamatan Bunaken.

\subsection{Ibu yang memiliki bayi usia 0-2 tahun setiap bulan mengikuti kegiatan pengasuhan balita dan pemenuhan gizi minimal satu bulan satu kali}

Jumlah responden yang memiliki bayi usia $0-2$ tahun berjumlah 30 Responden. yang menyatakan rutin setiap bulan mengikuti kegiatan pengasuhan balita dan pemenuhan gizi minimal satu bulan sekali hanya 3 orang (1\%). Alasan responden tidak mengikuti kegiatan pengasuhan balita adalah karena di lokasi tempat tinggal tidak pernah dilakukan kegiatan peyuluhan pengasuhan balita oleh pihak terkait dalam hal ini puskesmas atau posyandu.

\section{KESIMPULAN}

Peran perempuan dalam pencegahan stunting meliputi : memeriksa kehamilan 4 kali selama masa kehamilan, ibu hamil minum pil FE 90 butir selama masa kehamilan, hadir dalam konsling dan perawatan kehamilan, proses kehamilan ditangani oleh bidan, rutin hadir dalam posyandu, melakukan perawatan nifas oleh bidan/dokter, melakukan imunisasi lengkap setip bayi di atas 12 bulan, mengikuti kegiatan pengasuhan balita dan pemenuhan gizi minimal 1 bulan sekali. Dari delapan variabel peran perempuan dalam pencegahan stunting, variabel perempuan hadir dalam konseling perawatan kehamilan hanya $20 \%$ yang menyatakan rutin hadir. Dan variabel perempuan yang mengikuti pengasuhan balita dan pemenuhan gizi balita hanya $1 \%$ atau 3 orang responden. 


\section{DAFTAR PUSTAKA}

,Kementerian Kesehatan 2017. Hasil Pemantauan Gizi (PSG)

.Kementerian Desa dan Pembangunan daerah Tertinggal, 2017, Buku Saku

Desa Dalam Penanganan Stunting.

TNP2K Sekretariat Wakil Presiden, 2017, 100 Kab./kota Prioritas Untuk

Intervensi Anak Kerdil (Stunting).

Kemenkeu, 2018. Penanganan Stunting Terpadu.

Aswiyati, I. 1992. Gerak dan Dinamika Wanita dalam Pembangunan. Makalah.

Ernaini, Nanik. 1988. Pengaruh Modernisasi Terhadap Peranan Wanita dalam Keluarga. Jurusan Ilmu-Ilmu Sosial Ekonomi Pertanian. Institut Pertanian Bogor.

Ihromi, T.O. 1995. Wanita Sebagai Penerus Nilai- Nilai Kepada Generasi Muda. Prisma. Jakarta.

Mubyarto. 1997. Politik Pertanian dan Pembangunan. Penerbit Sinar Harapan Jakarta.

Munandar, U. 1995. Emansipasi dan Peran Ganda Wanita Indonesia. UI Press. Jakarta.

Notopuro, H. 1990. Peranan Wanita dalam Masa Pembangunan di Indonesia. Ghalia Indonesia. Jakarta.

Peck, J.C. 1991. Wanita dan Keluarga. Kanisius. Jakarta.

Sajogyo Pudjiwati. 1993. Peran Wanita dalam Perkembangan Masyarakat Desa. CV. Rajawali. Jakarta.

Sampoel, P. 1997. Peranan Wanita dalam Cipta dan Karsa Bagi Pembangunan Nasional. FISIP Unsrat. Manado.

Soemardjan, S. 1990. Manusia, Keluarga dan Masyarakat dalam Pembangunan. UI Press. Jakarta.

Suwondo, N. SH. 1991. Kedudukan Wanita Indonesia dalam Hukum dan Masyarakat. Ghalia Indonesia. Jakarta. 